\title{
Speed of writing and printing
}

\author{
SLATER E. NEWMAN \\ North Carolina State University, Raleigh, North Carolina 27650
}

\begin{abstract}
In Experiment 1, subjects printed the alphabet faster than they wrote it. In Experiment 2, copying of familiar words was equally fast when written or printed (in lowercase). Printing in uppercase was slowest. For both writing and printing, performance was faster on the word task than on the alphabet task, the fastest speeds ranging from 2.01 to 2.58 letters/sec. In both experiments, most subjects expressed a preference for writing over printing on tasks outside the laboratory.
\end{abstract}

The studies reported here were done to provide additional information about the writing speed of adult subjects. In a previous experiment (Newman \& Nicholson, 1976), subjects were given three trials to write the alphabet as quickly as they could. The results showed that on the third trial, subjects were producing approximately 2 letters/sec. Similar rates have been reported by Provins and Cunliffe (1972), by Provins and Glencross (1968), and by Weber, Kelley, and Little (1972).

In those three experiments, the task for the subjects was to write the alphabet, joining adjacent letters, as if writing a single 26-letter word. In the experiment by Newman and Nicholson (1976), however, subjects were allowed to choose whether they would write the alphabet, as in previous experiments, or print it. Half chose to do it each way, presumably selecting the type of response they believed to be faster. Examination of their performance indicated that there were no differences in speed between these two groups.

In the present experiments, all subjects were given both writing and printing trials. This permitted both within- and between-subjects comparisons of response speed. This also made it possible to determine the relationship between the speeds for these types of responding.

Different tasks were used in the two experiments. In Experiment 1, subjects printed the alphabet or wrote it as a single word, as in previous studies; in Experiment 2, subjects copied 20 familiar five-letter words as quickly as they could. The speed of printing in capital letters was also determined in Experiment 2. In each experiment, subjects were given three trials for each type of response.

\section{EXPERIMENT 1}

\section{Method}

Subjects and Design. The subjects were 24 undergraduates

I appreciate the help of Sandra Womack, who gathered the data in Experiment 1, and the comments of Michael Goodman. Requests for reprints should be sent to Slater E. Newman, Department of Psychology, North Carolina State University, Raleigh, North Carolina 27650. enrolled in an introductory psychology course at North Carolina State University. Subjects in Group PW were given the printing task first and then the writing task, and those in Group WP were given the writing task first. Printing was done in lowercase. Data were analyzed only for subjects who produced all 26 letters in the correct order on each trial and (in the writing task) joined all adjacent letters.

Procedure. Subjects were run individually. Each was given a lined sheet of paper and a ball-point pen and asked to write (or print) the alphabet legibly as fast as possible. Subjects were given three trials with one type of responding and then three trials with the other. Approximately $10 \mathrm{sec}$ separated the trials within the same response condition, and approximately $30 \mathrm{sec}$ elapsed when the response condition was changed. A stopwatch was used to record the time to the nearest $.1 \mathrm{sec}$. Following the last trial, subjects were asked whether they usually wrote or printed (1) when writing a letter to someone, (2) when taking notes in class, and (3) when trying to be as fast as possible.

\section{Results}

The mean letters per second for each of the writing and printing trials appear in Table 1 . Since there was little difference in the performance between the two groups, their scores were combined, and an analysis of variance was applied to the pooled data. The effects of response type and trials, but not their interaction, were significant [for response type, $\mathrm{F}(1,23)=17.52, \mathrm{p}<.01$, $\mathrm{MSe}=118.27$; for trials, $\mathrm{F}(2,46)=34.99, \mathrm{p}<.01$, $\mathrm{MSe}=3.38]$. Examination of the means indicates that printing was faster than writing and that both improved over trials. When each subject's fastest scores for each of the two response conditions were compared, the speed

Table 1

Mean Letters per Second for Writing and Printing in Each Experiment

\begin{tabular}{|c|c|c|c|c|c|c|c|c|c|}
\hline & \multicolumn{9}{|c|}{ Trial } \\
\hline & & & & & & Prin & ting & & \\
\hline & \multicolumn{3}{|c|}{ Writing } & \multicolumn{3}{|c|}{ Lowercase } & \multicolumn{3}{|c|}{ Uppercase } \\
\hline & 1 & 2 & 3 & 1 & 2 & 3 & 1 & 2 & 3 \\
\hline \multirow{3}{*}{$\begin{array}{l}\text { Group PW } \\
\text { Group WP }\end{array}$} & \multicolumn{9}{|c|}{ Experiment 1} \\
\hline & $\begin{array}{l}1.46 \\
1.24\end{array}$ & $\begin{array}{l}1.61 \\
1.54\end{array}$ & $\begin{array}{l}1.66 \\
1.54\end{array}$ & $\begin{array}{l}1.53 \\
1.65\end{array}$ & $\begin{array}{l}1.81 \\
1.83\end{array}$ & $\begin{array}{l}1.87 \\
1.92\end{array}$ & & & \\
\hline & \multicolumn{9}{|c|}{ Experiment 2} \\
\hline All Subjects & 2.11 & 2.14 & 2.15 & 1.93 & 2.01 & 2.07 & 1.55 & 1.65 & 1.68 \\
\hline
\end{tabular}


for printing was faster than for writing for 21 subjects, for 2 writing was faster, and for 1 subject there was no difference. For Group PW, the fastest speed ranged from 1.51 to 2.36 letters/sec for printing and 1.38 to 2.13 for writing; comparable values for Group WP were 1.44 to 2.41 and 1.07 to 2.03 .

Rank-order correlations were done separately for each treatment, using the subject's fastest score for each response type. For Group PW, the correlation was .799 $(\mathrm{p}<.01)$, and for Group WP, it was .245 ( $\mathrm{p}>.05)$. Rank-order correlations were also done for each group for each of the 15 possible pairs of trials. The results showed that for Group PW, the correlations involving trials within the same response condition ranged from .767 to .934 , whereas for trials involving different response types, the range was from .243 to .802 . For Group WP, the comparable values were .579 to .946 and -.066 to .799 . Thus all six of the correlations within the same response condition for each group were significant $(p<.05)$. Between response conditions, however, eight of nine were significant for Group PW, but only two of nine for Group WP.

In each group, nine subjects indicated that if speed were required they would choose to write rather than to print. In both groups, also, most of the subjects indicated that they would write rather than print in preparing a letter and in taking notes in class. For Group PW, nine preferred writing, one preferred print, and two had no preference for taking notes in class; for letters, nine again preferred writing, whereas two preferred print, and one had no preference. Corresponding values for Group WP were 10 who preferred writing and 2 printing for class notes, whereas 9 chose writing and 3 printing for preparing letters.

\section{Discussion}

The main finding of the present study is that subjects were faster in printing the alphabet than in writing it. This was the case for almost all of the subjects, most of whom, however, indicated that they preferred to write rather than to print, even if speed was to be stressed.

Writing and printing differ both in the way in which many of the letters are formed and in whether adjacent letters are joined. One implication of the latter difference is that speed of writing the alphabet might be more likely to be affected by the frequency of occurrence of adjacent letter pairs than would speed of printing the alphabet, with subjects writing faster the higher the frequency of adjacent pairs. Examination of the frequency of bigrams (Underwood \& Schulz, 1960) within the alphabet indicated that there were several of very low frequency. Thus the task chosen for Experiment 2 was one in which the average bigram frequency was substantially higher than that for the alphabet. It was expected that on such a task subjects would be more likely to write faster than they printed and that their performance would more closely match the preference most of them had expressed.

\section{EXPERIMENT 2}

The experimental task for this study was to copy 20 familiar five-letter words as quickly as possible. Three types of responding were compared, writing and lowercase printing, as in Experiment 1, and uppercase printing. Again, all subjects served in all treatments. Subjects were given three trials in each response condition.

\section{Method}

Subjects and Design. Twelve undergraduates enrolled in a course in introductory psychology at North Carolina State University served as subjects. Two subjects were assigned to each of the six possible orders for the three response conditions.

Materials. Twenty five-letter words were selected, 18 of which were in the AA frequency category of the ThorndikeLorge (1944) frequency count. For the other two words, the frequencies were 48 and 42 . The median bigram frequency (Underwood \& Schulz, 1960, pp. 333-335) of these words is 258 , with a range of $13-1,169$. (For the alphabet, the median bigram frequency is 3 , with a range of $0-608$.) In this list, each letter of the alphabet appears at least once, there are no double letters, and no letter begins more than one word. The words were listed in alphabetical order on the page, with a blank space beside each word. There were three columns on a page, one for each of the three trials in a response condition.

Procedure. The procedure was similar to that used in Experiment 1 , except that (1) subjects copied the words in a column rather than on a single line and (2) three rather than two response conditions were used.

\section{Results}

The mean letters per second for each response condition on each trial are presented in Table 1 . The data for all subjects were combined within a response condition, and an analysis of variance was performed on the pooled data. All three effects were significant [for response type, $\mathrm{F}(2,11)=20.52, \mathrm{p}<.01, \mathrm{MSe}=186.13$; for trials, $\mathrm{F}(2,22)=26.43, \mathrm{p}<.01$, MSe $=3.71$; for the interaction, $F(4,44)=3.29, \mathrm{p}<.01, \mathrm{MSe}=4.65]$. Examination of the means showed that the writing mean was somewhat, although not significantly, higher than the lowercase mean, and that both were lower $(p<.01)$ than the mean for the uppercase condition. The mean for all three groups declined over trials, but the decrease was greater for both printing conditions than for the writing condition. Within-subjects comparisons for the fastest speed within each condition showed that 7 of 12 subjects wrote faster than they printed (lowercase), 11 of 12 wrote faster than they printed (uppercase), and 11 of 12 printed faster in lowercase than in uppercase. The fastest speeds (letters per second) ranged from 1.72 to 2.58 for writing, from 1.67 to 2.53 for lowercase printing, and from 1.39 to 2.25 for uppercase printing. Rankorder correlations using each subject's fastest score in each condition gave correlations of .350 between writing and lowercase printing, .395 between writing and uppercase printing, and .169 between lowercase and uppercase printing. None of these correlations was significant $(p>.05)$.

Preference for writing compared with printing was evident also among subjects in this experiment. For preparing letters, 10 subjects favored writing, 1 favored lowercase printing, and 1 had no preference among the three response types. For taking notes in class, nine 
preferred writing and three lowercase printing, but when speed was required, seven favored writing, three lowercase printing, and two uppercase printing.

Rank-order correlations were also done involving each of the possible 36 pairs of trials. For correlations between trials within the same response condition, all nine were significant $(p<.01)$, the range being from .858 to .979 . For correlations between trials in different response conditions, however, only 2 of the 27 were significant $(\mathrm{p}<.05)$, the range being from -.084 to .533 .

\section{Discussion}

These experiments show that subjects printed faster than they wrote on the alphabet task, but on the word task, writing was somewhat, although not significantly, faster than lowercase printing. Both forms of responding were, however, faster than printing in uppercase letters.

Performance was faster on the word task than on the alphabet task for both writing and printing. There were, however, several differences between the two tasks, and it is not clear which of these differences contributed to this difference in performance. In addition to the fact that the comparisons are between experiments and thus involve different subjects (although all were drawn from the same subject pool), the following differences exist: (1) The alphabet was written on one line; the 20 words were written in a column. (2) Each letter occurs only once in the alphabet; in the word task, although each letter occurs at least once, some (perhaps those easiest to produce) occur more often. (The rank-order correlation between letter frequency on the word list and frequency of occurrence in print was .795.) (3) Average bigram frequency is higher in the words than in the alphabet. (4) The alphabet was produced from memory; the words were copied. And (5) the alphabet is longer than any of the words.

In all response conditions in both experiments, speed increased over trials, although the change over the first two trials was much greater than from Trial 2 to Trial 3. With additional trials, the speed would probably have continued to increase, although at a slower rate. The present results, combined with those from previous experiments (Newman \& Nicholson, 1976; Provins \& Cunliffe, 1972; Provins \& Glencross, 1968; Weber et al., 1972), suggest that the average performance in printing or writing, when the subject is trying to perform as fast as possible, is not likely to be much higher than 2 letters/sec. Similar results for digits have been reported by Newman and Nicholson (1976).

The correlation data show that within a response condition, there is some consistency in performance. Between response conditions, however, the results are mixed. In Experiment 1, there was a strong positive correlation between the two response conditions in Group PW. For Group WP, the correlation was also positive, but not significant. It is not clear why this betweentreatments difference in outcome occurred. In Experiment 2, performance in one response condition was not strongly related to performance in the others. It seems likely that the lower correlations in this experiment (compared with Experiment 1) derive from the pooling of data from subjects exposed to six different orders of the three tasks, whereas in Experiment 1, the correlations were done using data from just a single order of tasks within a treatment.

The questionnaire data are quite clear-cut. In both experiments, most subjects indicated that when speed is required, writing is the preferred response type. Their replies suggest also that most subjects are likely to have had more practice writing than printing. Even so, there was little difference in speed of performance on the word task, and in the alphabet task, performance was generally faster when subjects printed than when they wrote.

Newman and Nicholson (1976) have proposed that one way in which the results for response speed may be useful is as a guide for identifying the time to be allowed in experiments in which paced written responding is required (e.g., McCullers \& Haller, 1972; Shapiro \& Ponce, 1970). Since most such experiments use words, the results from Experiment 2 are the more appropriate. Examination of the results for writing and lowercase printing for each subject in that experiment indicates that the fastest time for the slowest subject was 2.01 letters/sec. These results suggest that when written responding is required, the test interval should be long enough that subjects who write (or print) no faster than 2 letters/sec can complete the task. This limit seems appropriate both for unpaced responding (in which, as in the usual free recall experiments, a fixed period of time is allowed for subjects to produce all the responses they can recall) and for paced responding (in which a fixed period of time is allowed for the production of each individual response).

Outside the laboratory, note taking during a lecture appears to present a situation with some of the characteristics of paced written responding. Since the optimal speaking rate is 125 150 words/min (Seabury, 1969), whereas the maximum writing (or printing) speed may be no more than $120-155 \mathrm{symbols} / \mathrm{min}$, it is evident that verbatim recording (as in a shadowing task) is not likely to occur. If the listener is to have a complete record of the lecture (one that can subsequently be accurately decoded), either some way of encoding the message other than spelling out each word completely must be used (e.g., abbreviation, speedwriting, shorthand) or the lecturer (perhaps in response to a signal from the listener) must speak very slowly or repeat the message. Although note taking during a lecture has been shown to enhance learning (DiVesta \& Gray, 1973), information is lacking about both the effect of (1) message variables (e.g., speed and structure of the lecture) on the way in which the listener graphically encodes it and (2) the method of encoding on recall. Future research on these problems seems desirable. Additional study of factors (e.g., bigram frequency, number of trials) that may affect the speed and accuracy of writing and printing also seems indicated.

\section{REFERENCES}

Divesta, F. J., \& Gray, G. S. Listening and note-taking: Immediate and delayed recall as a function of variations in thematic continuity, note-taking and length of retention interval. Journal of Educational Psychology, 1973, 64, 278-287.

McCulle rs, J. C., \& Haller, J. Another look at paced versus unpaced recall in free learning. Journal of Experimental Psychology, 1972, 92, 439-440.

Newman, S. E., \& Nicholson, L. R. Speed of oral and written responding. Bulletin of the Psychonomic Society, 1976, 7, 202-204.

Provins, K. A., \& Cunliffe, P. Motor performance tests of handedness and motivation. Perceptual and Motor Skills, 1972, 35, 143-150.

Provins, K. A., \& Glencross, D. J. Handwriting, typewriting and handedness. Quarterly Journal of Experimental Psychology, $1968,20,282-289$.

Seabury, H. F. Speech. In R. L. Ebel (Ed.), Encyclopedia of educational research (4th ed.). New York: Macmillan, 1969.

Shapiro, S. E., \& Ponce, I. Free recall and organization as functions of paced or unpaced responding and presentation rate. Psychonomic Science, 1970, 18, 329-330. 
Thorndike, E. L., \& LoRge, I. The teacher's word book of 30,000 words. New York: Bureau of Publications, Teachers College, Columbia University, 1944.

UNDE RWOOD, B. J., \& Schulz, R. W. Meaningfulness and verbal learning. Chicago: Lippincott, 1960.
Weber, R. J., Kelley J., \& Little, S. Is visual image sequencing under verbal control? Journal of Experimental Psychology, 1972, 96, 354-362.

(Received for publication August 17, 1980.) 